\title{
THERMIONIC GENERATOR FOR RE-ENTRY VEHICLES
}

by

Andre LeBlanc

W. W. Grarmemann

\section{LEGAL NOTICE}

This report was prepared as an account of Government sponsores work Nether the United Statoo, nor the Commisetion, nor any person acting on bebalf of the Comimlasion

A Makes any warrenty or representation, expressed or implied. with reapect to the accuracy, completeness, or usefuldoess of the information con tained in this report, or that the use
of any insormation, apparatus, method, or process diaclosed in thes report may not infr inge privately owned rights, or

B. Assumes any liabilities with rospect to the use or, or for damages resulting from the uos of any information, apperatus, method, or process disclosed in this report

As used in the above, "person acting on behalf of the commsssion" includes any employee or contractor of the Commlasion or employee of such contractor, to the extent tha dieseminates, or provides access to, any information pursciant to hise employment or contraci with the Commission, or bis employment with such contractor

\section{Eebruary 1963}




\section{DISCLAIMER}

This report was prepared as an account of work sponsored by an agency of the United States Government. Neither the United States Government nor any agency Thereof, nor any of their employees, makes any warranty, express or implied, or assumes any legal liability or responsibility for the accuracy, completeness, or usefulness of any information, apparatus, product, or process disclosed, or represents that its use would not infringe privately owned rights. Reference herein to any specific commercial product, process, or service by trade name, trademark, manufacturer, or otherwise does not necessarily constitute or imply its endorsement, recommendation, or favoring by the United States Government or any agency thereof. The views and opinions of authors expressed herein do not necessarily state or reflect those of the United States Government or any agency thereof. 


\section{DISCLAIMER}

Portions of this document may be illegible in electronic image products. Images are produced from the best available original document. 


\section{THERMONIC GENERATOR FOR RE-ENTRY VEHICLES* \\ Andre LaBlanc** W. W. Grannemann Electrical Engineering Department \\ University of New Mexico \\ Albuquerque, New Mexico}

\section{ABSTRACT}

A novel design of a thermionic generator for use on re-entry vehicles is analyzed analytically and experimentally. Equations are derived for prediction of the output current, output power, and conditions of maximum power for the device.

The electrical power output potential of a typical re-entry vehicle is obtained by solving the temperature history of a thin-walled emitter. Given the wall temperature and the work function, the saturated Richardson current is easily obiaired. other parameters needed for predicting output power are obtained from curves in the literature.

To simulate re-entry conditions, a test model was built and inserted in either a nitrogen or argon plasma jet. Graphite, thoriated tungsten, tungsten and molybdenum were used for the emitter and collector. Of the materials tested, graphite was the only material that met, to some degree, the qualifications needed for operation of the hypersonic plasma thermionic generator

* Research sponsored by Sandia Corporation, Albuquerque, New Mexic ** Now with IBM Essex Junction, Vermont 


\section{INTRODUCTION}

The study of direct energy conversion has become increasingly important during the last few years. Direct conversion of heat into electrical energy offers many advantages for space applications over indirect conversion methods, the light weight of a direct converter being only one. Beginning with the well-known assertion that thermionic emission from a metal is accompanied by peltier cooling of the metal interface ${ }^{l}$, and using the converse theory that states the acceptance of electrons by a metal is accompanied by peltier heating, the interface between a metal and an ionized gas may be treated as a junction between two conductors-the plasma forming one branch and the remainder of the circuit forming the other.

In just such a fashion, H.W. Lewis and J.R. Reitz ${ }^{2}$ treated the thermionic generator as a thermocouple, using transport theory to calculate the seebeck emf or oper circuit voltage. Their anjysis pointed out that any two surfaces separated by a fairiy dense plasma with one surface hot enough to emit electrons should operate as a plasma thermionic converter.

A missile re-entering the atmósphere is known to have for a period of time a fairly dense plasma surrounding the body

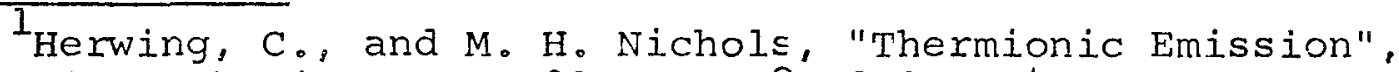
Rev. Modern Physics, Vol。21, pp. 185-270, 1949.

Lewis, $H_{0} W_{0}$ and $J . R . R e i t z, " T h e r m o e l e c t r i c$ Properties of the Plasma Diode," Journal of Appl. Physics, Vol.30, pp. 1439-45, 1959.
} 
and also a temperature differential on the surface. As long as the vehicle travels at supersonic speeds the affected region is enclosed in the bow shockwave. At sufficiently high shock-layer temperature the air dissociates and ionizes. The highest heating rate occurs at the stagnation point and results in the nose of the vehicle being maintained at a considerably higher temperature than the remainder of the body. The nose can therefore act as an electron emitter, and the body of the vehicle can act as the electron collector. An electrical insulator is inserted between the emitter and collector as shown in Figure. 1 .

A device very similar to Figure 1 was inserted in an ionized argon plasma jet by I. Cotter ${ }^{3}$. Although the duration of the run was quite short, the experiment shoved a current existing for a short period of time, and also indicated an open circuit voltage of the expected polarity.

This paper describes a study of a hypersonic plasma thermionic generator considered theoretically and experimentally. Electrical parameters of the experimertal device were obtained by writing a set of balanced current equations at the emitter and at the collector using a Kirchhoff voltage equation for the complete electrical loop. The current equations were obtained by treating the ionized gas as a fairly dense plasma that tends to emit as well as to accept electrons. The electron current from the metal to the plasma is defined using the familiar Richardson current; the electron current from the plasma to the emitter is 
obtained by calculating the flux of electrons emitted from an ionized gas, whereby the electrons have a Maxwellian distribution and have to overcome a barrier equal to the plasma sheath potential existing at the emitter or collector. From these two sets of equations, the output voltage, $V$, the output current, I, the emitter sheath potential, $V_{e}$ the collector sheath potential, $\mathrm{V}_{\mathrm{a}}$, and the output power of the device are calculated. A somewhat similar set of equations was obtained by carabateas 4 for a planar diode.

\footnotetext{
${ }^{4}$ Carabatess, E. N, pezaris, S. D., ari G. N. Hatsopoulos, "Interpretation of Experimertia Chanacteristias of Cestum Thermionic Corverte:s," Jourral of Appl. Fhysizs, Toi. 32, pp. 352-358, 1961 .
} 


\section{$-4-$ \\ THEORETICAL ANALYSIS OF THE PLASMA MODE}

To operate in the plasma mode, the minimum rate at which the ions produced within the bow shockwave must arrive at the emitter should equal the square root of the ratio of the mass of the electron to the mass of the ion times the electron current:

$$
J_{i}=J_{e} \sqrt{\frac{m_{e}}{m_{i}}} ;
$$

where

and

$$
\begin{aligned}
& J_{i} \text { is the ion current density, } \\
& J_{e} \text { is the electron current density, } \\
& m_{e} \text { is the mass of the electron, }
\end{aligned}
$$$$
m_{i} \text { is the mass of the ion. }
$$$$
\text { For argon gas, the mass of an argon ion is equal to }
$$$$
\text { (6.65) (10) })^{-23} \text { grams, and the mass of an electron is (.911) }
$$$$
\text { (10) }-27 \text { grams. The ion arrival rate should therefore be at }
$$

least 1/293th the electron emission rate for the elimination of electron space cinarge. For high temperature air the two main sources of ions are the oxygen and nitrogen ions. The mass of the oxygen ion is $(2.66)(10)^{-23}$ grams, and the mass of the nitrogen ion is $(2.33)(10)^{-23}$ grams, giving an average mass of approximately $(2.5)(10)^{-23}$ grams. The ion arrival rate for air should therefore be at least $1 / 155$ th the electron emission rate.

In the calcuiation of the ion arrival rate as compared to the electron emission rate and also of the mean-free path of 
the electrons for the hypersonic plasma thermionic generator, it will be seen that it is operating as a plasma converter. The following discussion and derivation will therefore assume this condition to be existing for the device.

The net current at the emitter side can be expressed in terms of the random ion and electron current from the plasma to the emitter plus the Richardson current from the emitter to the plasma. Therefore, one has:

$$
I=I_{s}-I_{e}+I_{p 1}
$$

where,

I is the net current in the generator,

$I_{\mathbf{S}}$ is the saturated Richardson current.

$I_{e}$ is the random electron current from the plasma to the emitter,

$I_{p l}$ is the ion current at the emitter.

The random electron current from the plasma to the emitter can be derived by assuming a Maxwellian distribution for the electrons in the plasma and a step potentiai $V_{e}$ existing at the emitter boundary:

$$
I_{e}=e r_{E} \sqrt{\frac{k T_{e}}{2 \pi m_{e}}} A_{e} \exp -\left(\frac{e V_{e}}{k T_{e}}\right) ;
$$

where,

$\mathrm{n}_{\bar{e}}$ is the electron density in the plasma,

$T_{e}$ is the electron temperature,

and

$A_{e}$ is the area of the emitter. 
The positive sheath potential, $V_{e}$ is formed when the ion production rate becomes so much greater than that required for space charge neutralization that an ion sheath forms at the surface of the emitter. Near the boundaries of the ionized space, the electrons, with their high value of the coefficient of diffusion, $\mathrm{D}_{\mathrm{e}}$, move away from the point of creation more rapidly than the slower positive ions with coefficients of diffusion, $D_{i}$. The diffusion of the negative electronic charge away from the neutral plasma quickly builds up a negative space charge on the surface and leaves a positive ion space charge in the inner volume located right next to the boundary.

The saturated ior current is equal to:

$$
I_{p l}=\frac{q N_{i} \bar{v}_{i} A_{e}}{4}
$$

where $\bar{v}_{i}$ is the average thermal velocity of the ion. The ion current at the emitter and collector is always at its saturated value and is therefore a constant for a constant ion dersity and a constant ion temperature.

At the collector side the same net current, I, exists. This current will corsist of a random electron current from the plasma to the collector minus the saturated ion current. Therefore, at the collector:

$$
I=I_{a}-I_{p 2}
$$


where,

I is the random electron current from the plasma to the
collector. $I_{\mathrm{p} 2}$ is the saturated ion current at the collector.

The random electron current, $I_{a^{\prime}}$ is equal to:

$$
I_{a}=n_{\bar{e}}\left(\frac{k T_{e}}{2 \pi m_{e}}\right)^{/ / 2} A_{a} \exp -\frac{e V_{a}}{\frac{k T_{e}}{T_{e}} ;}
$$

where,

A $a$ is the area of the collector.

$\mathrm{V}_{\mathrm{a}}$ is the collector sheath potential.

A voltage equation can be written for the complete electrical loop of the generator:

$$
v_{t}+\varphi_{a}-v_{a}-\varphi_{e}+v_{e}=0
$$

where,

$\varphi_{a}$ is the collector work function,

$\varphi_{e}$ is the emitter work function,

$V_{t}$ is the voltage arop in the plasma plus the voltage drop across the load.

Rewriting equation $(\bar{Z})$ ?

$$
I_{e}=I_{s}+I_{p l}-I_{s}
$$

and inserting the definition of $I_{e}$ from equation (3) into (2'):

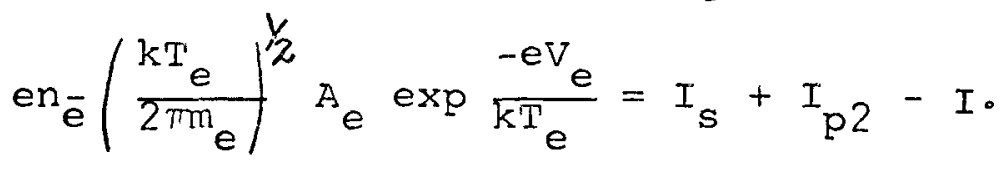

Rewriting equation (5):

$$
I_{a}=I+I_{p 2}
$$

and inserting the definition of $I_{a}$ from equation (6) into (5'): 


$$
\text { en } n_{\bar{e}}\left(\frac{k T_{e}}{2 \pi m_{e}}\right)^{/ 2} A_{a} \exp \frac{-e V_{a}}{k T_{e}}=I+I_{p 2} \text {. }
$$

If equation ( $2^{\prime \prime}$ ) is now divided by equation $\left(5^{\prime \prime}\right)$ one obtains:

$$
\frac{e}{k T_{e}}\left(V_{a}-V_{e}\right)=\ln \left[\frac{A_{a}}{A_{e}}\left(\frac{I_{s}+I_{p I}-I}{I+I_{p 2}}\right)\right] \text {. }
$$

Inserting the definition of $\mathrm{v}_{a}-\mathrm{v}_{e}$ from equation (7) into equation (8) results in:

$$
V=\frac{k T_{e}}{e} \ln \left[\frac{A_{a}}{A_{e}}\left(\frac{I_{s}+I_{p l}-I}{I+I_{p 2}}\right)\right]-I x+\varphi_{e}-\varphi_{a} ;
$$

where $r$ is the resistance of the plasma.

In equation 9 the term " $\mathrm{T}$ " is the electron temperature existing in the bourdary layer surrounding the generator. The reason for using this value of $\mathrm{T}_{e}$ is that the emitter surface is relatively cool when compared to the gas temperature surrounding it, and also the accelerating $v_{e}$ is low enough in magnitude so that the equivalent temperature of the electron as it enters the plasma is still below the gas temperature. With the mean-free path of the electrons much smallex than the spacing between emitter and collector, the emitted electron soon reaches thermal equilibrium with the surrounding gas. Equation 9 can be rewritten as:

$\ln \left[\begin{array}{ll}A_{a} & \left(I_{s}+I_{p l}-I\right) \\ \bar{A}_{e} & \left(I+I_{p 2}\right)\end{array}\right]=\frac{e}{k T_{e}} V+e \frac{\left(\varphi_{a}-\varphi_{e}\right)}{k T_{e}}+\frac{e}{k T_{e}}$ Ir, (9') 
If the resistivity of the plasma is negligible, equation 9' is the equation of a straight line with a slope equal to $\frac{e}{\mathrm{kT}_{\mathrm{e}}}$. In an experimental set-up, the current and voltage of the device can be measured. The current"I $+I_{p} I^{\prime}$ is obtained by applying a positive potential on the collector; while the ion current "I p2" is obtained by applying a negative potential on the collector, the net current. I, is varied by means of a resistive load. With a knowledge of these parameters equation 9 can be plotted on a semi-logarithmic paper. The slope of this line should yield $T_{e}$ and the intersection of the plotted line with the horizontal line $Y=1$ gives $\varphi_{e}-\varphi_{a}$, where

$$
\gamma=\frac{A_{a}}{A_{e}}\left(\frac{I_{s}+I_{p 1}-I}{I+I_{p 2}}\right) \text {. }
$$

The power output of the device is obtained by multiplying equation (9) by I:

$$
P=\frac{k T e}{e} I \ln \left[\frac{A_{a}}{A_{e}} \frac{\left(I_{s}+I_{p l}-I\right)}{\left(I+I_{p 2}\right)}\right]-I^{2} r+I\left(\varphi_{e}-\varphi_{a}\right)
$$

The location of maximum power output, $P$ max, as a function of the net current $I$ is obtained by differentiating equation (10) with respect to I and setting the result equal to zero:

$$
\begin{aligned}
\frac{d P}{d I}=0= & \frac{k T_{e}}{e} \ln \left[\frac{A_{a}}{A_{e}}\left(\frac{I_{s}+I_{p l}-I}{I+I_{p 2}}\right)\right]-\frac{k T_{e}}{e} \frac{I\left(I_{p 2}+I_{s}+I_{p l}\right)}{\left(I+I_{p 2}\right)\left(I_{s}+I_{p 1}-I\right)} \\
& -2 I r+\varphi_{e}-\varphi_{a} \cdot
\end{aligned}
$$

Solving equation (11) for $\frac{k T e}{e} \ln \left[\frac{A_{a}}{A_{e}} \frac{\left(I_{s}+I_{p l}-I\right)}{\left(I+I_{p 2}\right)}\right]$ one obtains 
$\frac{k T_{e}}{e} \ln \left[\frac{A_{a}}{\bar{A}_{e}} \frac{\left(I_{s}+I_{p 1}-I\right)}{\left(I+I_{p 2}\right)}\right]=\frac{k T_{e}}{e} \frac{I\left(I_{p 2}+I_{s}+I_{p 1}\right)}{\left(I+I_{p 2}\right)\left(I_{s}+I_{p 1}-I\right)}+2 I r+\varphi_{a}-\varphi_{e} \cdot$

Inserting equation (12) into equation (10):

$$
P_{\max }=I_{\alpha}^{2} \frac{k T_{e}}{e} \frac{\left(I_{p 2}+I_{s}+I_{p 1}\right)}{\left(I_{s}+I_{p 1}-I_{\alpha}\right)\left(I_{\alpha}+I_{p 2}\right)}+I_{\alpha}^{2} r \text {. }
$$

where $I_{\alpha}$ is the current corresponding to $P_{\max }{ }^{\circ}$

To better appreciate the effect of $\mathrm{I}_{\mathbf{s}}$ on $\mathrm{P}_{\text {max }}$, the ion currents are assumed negligible and equation (13) is rewritten:

$$
P_{\max }=I_{\alpha} \frac{k T_{e}}{e}\left[\frac{I}{I-I_{\alpha} / I_{s}}\right]+I_{\alpha}^{2} r \text {. }
$$

In order to increase the maximum power, the saturated Richardson current should be as high as is feasible.

If one now assumes that the current, $I_{S^{\prime}}$ is fixed, an interesting observation would be to find the ratio of $I / I_{s}$ when maximum power occurs. In order to obtain some idea of this value, the resistivity of the plasma is assumed negligible, and the work function of the emitter is assumed equal to the work function of the collector. With these assumptions, equation (12) reduces to:

$$
\ln \left[\frac{\frac{A_{a}}{A_{e}}\left(\frac{I_{s}+I_{p 1}-I_{j}}{I_{s}}\right)}{\frac{I+I_{p 2}}{I_{s}}}\right]=\frac{I / I_{s}\left(\frac{I_{p 2}+I_{p 1}}{I_{s}}+1\right)}{\left(1+\frac{I_{p 1}-I}{I_{s}}\right)\left(\frac{I+I_{p 2}}{I_{s}}\right)} .
$$

The solution of equation (15) has been obtained by graphical analysis and is shown in Figure 2 for various values of $I_{p l}$ and $I_{\mathrm{p} 2} \cdot$ 
Where

$$
\lambda=\ln \frac{\bar{A}_{e}\left(\frac{I_{s}+I_{p 1}-I}{I_{s}}\right)}{\frac{I+I_{p 2}}{I_{s}}} \text {, and } \quad \gamma=\frac{\frac{I}{I_{s}}\left(\frac{I_{p 2}+I_{p 1}}{I_{s}}+1\right)}{\left(1+\frac{I_{p 1}}{I_{s}}\right)\left(\frac{I+I_{p 2}}{I_{s}}\right)} \text {. }
$$

One will notice that the ion currents have very little effect in determining the point where $P_{\max }$ occurs. The introduction of $\varphi_{e}-\varphi_{a}$ in equation (15) would shift the maximum power point to the left if $\varphi_{a}<\varphi_{e}$ and vice versa if $\varphi_{e}<\varphi_{a}$. If the resistivity of the plasma is significant its effect would be to shift $P_{\max }$ to the right. 
PREDICTING THE ELECTRICAL POWER OUTPUT FOR A RE-ENTRY VEHICIE

To obtain the temperature of the emitter or nose, it will be assumed that the heat sink capabilities of the emitter are negligible in comparison to the total amount of energy involved. For this particular situation, this condition is satisfied by having a very thin material for the emitter. The thermal radiation from the gas to the body will also be neglected. Under these conditions the rate of convective heat transfer rate from the gas to the body, plus the rate of heat added to the body due to electron-ion recombination on the surface must equal the radiated heat from the body to the plasma, plus the rate of electron cooling due to emitted electron current.

The following equation can therefore be written:

$$
q_{S}+\frac{q_{i-e}}{11380}=\frac{\sigma \varepsilon_{h} T_{\omega}^{4}}{11380}+\frac{I_{R}\left(\varphi_{e}+2 k T_{\omega}\right)}{11380} ;
$$

where,

$q_{s}$ is the convective heat transfer rate from the plasma to the body,

$q_{i-e}$ is the rate of heat added to the body due to electronion recombination on the surface,

$\sigma$ is the Stephan-Boltzmann constant,

$$
(5.67)(10)^{-8} \frac{\text { watts }}{\text { meter }^{2}(\operatorname{deg} K)^{4}} \text {, }
$$

$\varepsilon_{h}$ is the emissivity of the heat sink surfaces,

$T_{\omega}$ is the wall temperature or the temperature of the emitter in degrees Kelvin.

$I_{R}$ is the Richardson electron current in $\frac{\text { amperes }}{\text { meter }^{2}}$, 
$\varphi_{e}$ is the work function of the emitter in electron-volts,

11380 is the conversion constant from watts/meter ${ }^{2}$ to $\mathrm{BTU} / \mathrm{sec}-\mathrm{ft}^{2}$.

The equations for obtaining the convective heat transfer rate have been formulated exactly and solved numerically by a computer. 5 A correlation of the numerical results was then made which produced the following formula for computing convective heat transfer rates at the stagnation point:

$$
q_{s}=20800\left(\frac{p}{R p_{0}}\right)^{1 / 2}\left(\frac{V}{v_{e}}\right)^{3.25}\left(1-\frac{h}{h_{e}}\right) \frac{B T U}{f t^{2}-\sec }
$$

where,

$\mathrm{R}$ is the nose radius in the meridional plane,

$\rho_{0}$ is the mass density at standard atmosphere,

$h_{\omega}$ is the enthalpy at the wall per unit mass,

$\mathrm{h}$ is the enthalpy at the edge of the boundary layer
per unit mass.

To obtain the re-entry velocity as a function of altitude, the vehicle is assumed to be subjected only to a drag force. With this condition existing, the flight path angle during entry will remain constant. In actuality, however, the trajectory is slightly curved. This problem has been computed several times before ${ }^{6}$ and the equation that results is:

5emp, N. H., and F. R. Riddell, "Heat Transfer to satellite Vehicles Re-entering the Atmosphere," Jet Propulsion, vol. 27, part 1, February, 1957, pp. 132-137, 147.

6 Wagner, c., "The Skin Temperature of Missiles Entering the Atmosphere at Hypersonic speed," TR 60, Ordnance Research and Development Division, Sub-office, Fort Bliss, Texas, sept., 1949. 


$$
V=V_{e} e^{-B e^{-y / H}}
$$

where,

$v_{e}$ is the initial velocity at re-entry,

$$
\begin{aligned}
& B=\frac{H \rho_{e}^{g C} d^{A}}{2 W \sin \theta}, \\
& Y \quad \text { is altitude in } f t ., \\
& H \text { is } 21400 \mathrm{ft} . \\
& \rho_{e} \text { is .00363 slugs/ft }{ }^{3}, \\
& C_{d} \text { is the hypersonic drag coefficient. }
\end{aligned}
$$

A is the area 2 on which the drag coefficient is based in $\mathrm{ft}^{2}$.

$w$ is the weight of the re-entry vehicle, Ib.

$\theta$ is the entry flight path angle, measured from the horizontal.

9 is $32.2 \mathrm{ft} / \mathrm{sec}^{2}$.

The density as a function of altitude can be approximated by an exponential, that is:

$$
p=p_{e} e^{-y / H}
$$

where according to sutton ${ }^{7}$ for $\rho_{e}=.00363$ slugs $/ \mathrm{ft}^{3}$ and $\mathrm{H}=21400 \mathrm{ft}$. the maximum error in $P$ is six percent compared to standard atmosphere.

substituting equation (18) and,(19) into equation (17) one obtains the convective heat transfer rate as a function of altitude:

7 Sutton, G., "The Temperature History in a Thick Skin Subjected to Laminar Heating During Entry into the Atmosphere," Jet Propulsion, pp.10-45. January, 1958. 


$$
q_{s}=20800\left(\frac{\rho_{e}}{\rho_{o}}\right)^{1 / 2}\left(\frac{V_{e}}{V_{s}}\right) 3.25\left(1-\frac{h_{\omega}}{h_{e}}\right) e^{-\left(y / 2 H+3.25 B e^{-y / H}\right)}
$$

where $V_{s}$ is the sea level satellite velocity in $\mathrm{ft} / \mathrm{sec}$.

The heat transfer due to ion-electron recombination at the emitter surface is the product of the ion flux into the sheath and the energy of recombination per ion. Thus:

$$
q_{i-e}=\frac{1}{4} \frac{h_{i-e}\left(n_{i} \bar{v}_{i}\right)(3.28)(1728)(16.39)}{(1054.8)} \frac{B T U}{1 t^{2}-\text { sec }}
$$

where

$\mathrm{h}_{\text {i-e }}$ is the energy of ionization,

$\bar{v}_{i} \quad$ is the average thermal velocity in meters/sec.

The assumption was made that recombination occurred to the ground state. The ionization potential of oxygen is 13.62 e.v., while that of nitrogen is $14.55 \mathrm{e} . \mathrm{v}_{0}$, giving an average value of $14.36 \mathrm{e} . \mathrm{v}$. The average value was obtained by assuming $80 \%$ nitrogen and $20 \%$ oxygen.

By definition, the saturated Richardson current is equal to:

$$
I_{R}=\frac{A_{0} T_{\omega}^{2}}{11380} \exp \frac{-e \varphi_{e}}{k T_{\omega}}
$$

where $A_{0}$ is a constant involved with electron emission, amps/meter ${ }^{2}-(\text { degree } K)^{2}$.

Reinserting the definition of $q_{S}, I_{R^{\prime}}$ and $q_{i-e}$ into equation $(16)$ :

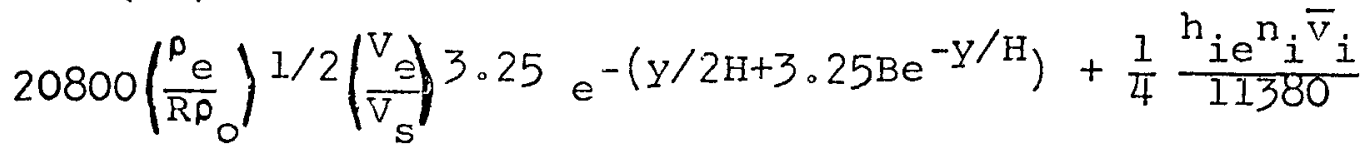

$$
\begin{aligned}
& =\frac{\sigma \varepsilon_{h^{T}} T^{4}}{11380}+\frac{A_{0} \mathrm{~T}^{2}}{11380}\left(\exp \frac{-e \varphi_{e}}{k T_{\omega}}\right)\left(\varphi_{e}+2 k T_{\omega}\right) \text {. }
\end{aligned}
$$


Since the equation for convective heat transfer rate applies only at the stagnation point, the nose of the vehicle was assumed to be blunt thereby giving a better indication of the emitter temperature. With the emitter confined to the blunt part of the vehicle, the convective heat transfer rate, as well as the density, temperature, and ion density, can be approximated as being nearly equal to the stagnation value. with the convective heat transfer rate known, it is also possible to determire the wall or emitter temperature through the use of equation (16)。 As previously mentioned, the equation neglects the heat capacity of the material.

An indication of the magnitude of $q_{S}$ was obtained by assuming the following constants:

$$
\begin{aligned}
& R=10 \mathrm{ft} \\
& \rho_{e}=.00363 \mathrm{slugs} / \mathrm{ft}^{3} \\
& P_{0}=.002375 \mathrm{sl} \mathrm{gs} / \mathrm{ft}^{3} \\
& \mathrm{~V}_{\mathrm{e}}=25000 \mathrm{ft} / \mathrm{sec} . \\
& \mathrm{V}_{\mathrm{s}}=5000 \mathrm{ft} / \mathrm{se}= \\
& \mathrm{H}=21400 \mathrm{ft} . \\
& \mathrm{g}=32.2 \mathrm{ft} / \mathrm{sec}^{2} .
\end{aligned}
$$

The correction factor $\left(1-h^{h} / h\right)$ was obtained from a Mollier diagram ${ }^{8}$. Sirce the temperature of the wall is considerably lower than the surrounding gas temperature, the ratio $h_{\omega} / h_{e}$ did not exceed 0.2 . When the convective heat

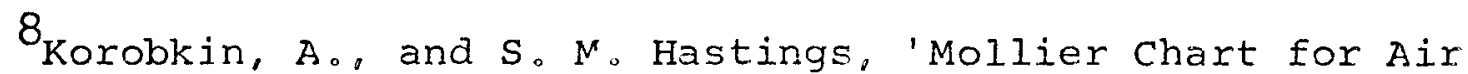
in Dissociated Equilibrium at Temperatures of $20000 \mathrm{~K}$ to 150000 K", NAVORD Report 4446, May 23, 1957. 
transfer rate exceeded the maximum radiated heat rate plus electron cooling, the factor $1-h^{h} / h_{e}$ was neglected, since the correction did not affect $T_{\omega}$ 。

The heat transfer due to ion-electron recombination at the emitter surface was obtained from equation (21)。The average thermal velocity was calculated from temperature measurements as obtained by $\mathrm{Sisco}$ and Fiskin ${ }^{9}$ for equilibrium air near the stagnation point.

The calculation of the saturated Ruchardson current was divided into two mair regions. In the first region, the convective heat transfer rate plus the heat rate due to electronion recombination was less than the sum of radiated heat rate and electron cooling. As long as this condition existed, it was possible to use equation (23) for predicting the wall temperature. This equation was solved by an iteration process on $\mathrm{T}_{\omega}$. knowing the wall temperature, it was then possible to calculate the expected saturated Richardson currer.t. In the second region. the sum of convective heat transfer rate plus the heat rate due to electron-ion recombination was sufficiently larger than the radisted heat rate plus the electron cooling to permit assumption that the wall temperature would remain constant at its ablation value.

To obtain the output voltage and output current, equation (9) was utilized. In these calculations, the resistivity of

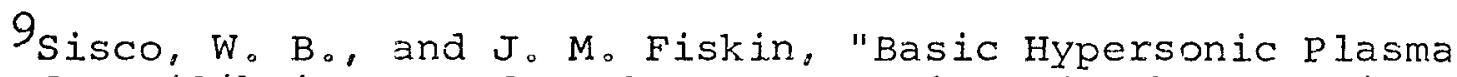
Data of Equilibrium AIr for Electromagnetic and other Requirements," planetary and space scierce, vol.6. p。47-73. 
the plasma was neglected. The difference in work functions, $\varphi_{e}-\varphi_{a}$, was obtained for graphite from experimental data to be in approximately $-0.4 \mathrm{e} . \mathrm{V}$. The current, I, was based on generator operation near the region of maximum power. For graphite, the current ratio, I/I , for this condition was 0.1748 . The low value of this ratio as compared to the theoretical value of 0.21 was mainly due to the effect of the negative term $\varphi_{e}-\varphi_{a}$ 。

A typical set of the computed results for $\theta=30^{\circ}$, $\mathrm{W} / \mathrm{C}_{\mathrm{D}} \mathrm{A}=100, \varphi_{\mathrm{e}}=4.7 \mathrm{e} \cdot \mathrm{v}_{\circ}, \mathrm{A}_{\mathrm{O}}=(60.2)(10)^{4}$ amps, and $\varphi_{e}-\varphi_{a}=-.4 \mathrm{e} . \mathrm{V}$ o are shown in Table 1 。 
Spatial Configurations

The requirements of maximum power output per unit volume and minimum collector heating can be satisfied by means of a hemispherical shell attached to a cylindrical body. Figure 2 shows a cross-sectional view.

The radius of the hemispherical shell in the meridional plane should be large when compared to the diameter of the cylinder. This is nesded in order to have a high convective heat transfer rate and a high ion density at the emitter. The length of the separator should be made as short as possible. This assumes the insulator to be a poor heat conductor. By decreasing the length, the resistivity of the plasma near the collector can be near erough the forward end of the re-entry body to permit the electron density to still be sufficiently high.

From the graphs given by Lees, the heating rate is practically a constant along the cylindrical portion of the bcoy. Therefore, even though the length of the separator is short, the convective heat transfer rate to the collector shoild not increase.

To assure that the emitter is operating at or near its ablating temperature, the nose shell should be very thin. This will decrease the heat capacity of the emitter as well as decrease the total weight of the generator. The collector, however, should have a high enough heat capacity to prevent any back current. 
Experimental Models

Due to the large number of problems that arise in construction of the hypersonic plasma thermionic generator, it was decided that a large portion of the research program would be devoted to a feasibility study. In addition to showing feasibility, the experimental results would be used to verify to some degree the furdamental assimptions used in the foregcing analysis.

For simplicity, it was decided to construct models for which hypersonic flow characteristics had been either solved analytically or obtained experimentally. The basic problem was to study the device from an electrical point of view.

The emissive materials used in the models were thoriated tungsten, tungsten, molybdenim, and graphite. The same grcup of materials was utinized for the collector. The insilators were composed of $96 \%$ azumina. This material possesses a very high resistivity and very pocr allating characteristics.

\section{Experimental Apparat:s}

The apparatus used to stidy the hypersonic plasma thermioric generator is built around an evaciated chamber. The chamber was fitted with a large reirforced windciw which permitted detailed viewing of the generator in operaticn. The erclosire of the model in the chamber allowed one to control, to some degree, the environmertal conditions. 
Plasma Generator

A Giannini Plasmadyne arc plasma generator model M-4 was utilized for all tests. This generator has a maximum capacity of 120 kilowatts.

Hypersonic Nozzle

A conical nozzle with an area ratio of 3.88 from outlet to throat was utilized for all tests. The nozzle was theoretically designed for a mach number of 3.4. In actual operation, the mach number was closer to 2 .

\section{Experimental Procedure}

The arc plasma was turned on without the model in the jet. This was felt necessary since a considerable amount of copper vapor was contained in the plasma when the power was first turned on. The power was then brought up to the desired value and the model lowered into the stream.

The short circuit currert was the first parameter to be measured. Approximately 20 seconds would elapse before the generator and lead-in wires reached thermal equilibrium. After reaching equilibrium, the current would reach a steady state value. A variable resistive load was then utilized for obtaining the volt-ampere curve of the model.

The saturated Richardson current plus ion current at the emitter was obtained by applying a variable positive potential on the collector. This measurement was quite sensitive due to the fact that, if the potential was too high, an arc would form between emitter and collector. When this condition occurred, 
excessive currents would flow. The ion current at the collector was measured by simply reversing the battery potential and current switch. All measurements were made with the system in a floating condition.

The following quantities were measured:

1. The net current existing with a variable resistive load.

2. The saturated Richardson current plus ion current at the emitter.

3. The ion current at the collector.

4. The potential difference between emitter and collector.

5. The potential difference across the battery.

6. The arc chamber pressure.

7. The test chamber pressure.

8. The input power to the arc plasma.

9. The flow rate of the gas.

10. The elapsed time for a complete operation at one input power level.

11. The water temperature at the input and output.

12. The water pressire at input and output.

13. The flow rate of water.

Experimental Results

Table 2 shows experimental results obtained with a graphite emitter and graphite collector. Table 3 shows the corresponding calculated results. Figure 4 shows the output voltage versis current and Figure 5 shows a plot of power versus current. 
There was no Page 23 located in original document. 
picked up this increase in energy from the acceleration of the emitter sheath potertial, $v_{e}$, or else it was obtained from the collision process in the gas.

The difference in work function. $\varphi_{e}-\varphi_{a}$, was negative for all graphite emitters and collectors except one. This would seem to indicate that the work function of this materiai decreases as the temperature increases. Graphite, being a semiconductor, will have an increase in the number of electrons in the conduction kard as the temperature rises. The Fermi. level will therefore rore toward the conduction band, resulting in a lower work function.

The one exception cccurred at a very high input power to the plasma. The difference in work function for this case was zero. A possibie expianation of this condition is the rise in temperature of the collector. This temperature increase. which was cbservable by the glow of the ccilector body, results also in a decrease of the work function.

Tables 4 and 5 show the results of a thoriated turgsten emitter and graphite ccliestor. Two rather surprising facts occurred when the inf versis cutput voltage curve was plotted. The first was a drastic drop in electron temperature, ard the second was the differerce, $\varphi_{e}-\varphi_{a}$, as a pcsitive number.

A possible explaration of this condition would be the decrease in the accelerating emitter sheath potential. Arcther factor which could decrease the electron temperature is the

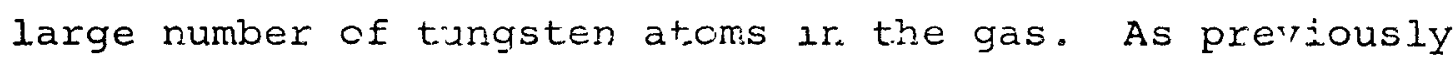
indicated, tungsten was deposited on the insulator as well as 
on the collector, since the tungsten atoms are coming from the emitter, their temperature is considerably lower than the surrounding gas. Their effect should then be to cool the plasma. The cooling effect did in fact increase the resistivity of the gas. This was observable to some degree by the tendency of the Iny versus output voltage plot to curve upward at low values of load impedance.

The value of the ion current at the emitter was obtained by first calculating the ion density at the collector from $I_{p 2}$. The ion density at the stagnation point was assumed to be approximately $1 \%$ the argon density existing at that point. This percentage was obtained by spectographic means。 11 An inspection of the theoretical values of ion density existing along the body, as obtaired by various authors revealed that the average value was smaller by a factor of 10 over the emitter surface relative to the value at the stagnation point. This was fairly consistent for the emitter areas of $10 \mathrm{~cm}^{2}$ utilized in this experiment. Knowing the density and temperature, it was then possible to calculate the ion flux. The highest saturated current density attained was 1.423 amps/sq $\mathrm{cm}$ for an emitter temperature of $2288.5^{\circ} \mathrm{K}$. Correspondingly, the highest power density obtained was 0.45 watts/ sq $\mathrm{cm}$. Due to the melting of set screws utilized for holding the graphite emitters, it proved impossible to attain the current density corresponding to the ablating temperitures.

${ }^{11}$ see reference 10 . 


\section{APPARATUS, METHODS AND CONCLUSIONS}

\section{Emissive Materials}

In choosing the emissive materials, the following factors were considered:

1. The emitter should be a material producing a high saturated Richardson electron current. The large emitted current gives an increase in power output as well as an increase in electron cooling. Since the ion density surrounding the emitter must be sufficient to overcome the electron space charge cloud caused by electron emission, a lower limit is imposed on the work function of this material.

2. The emitter should have good ablating properties since the convective heat rate is normally well above the heat capacity of a thin sheet material and the heat radiated from the nose.

3. The material should be reasonably machinable.

4. The material should possess a high coefficient of emissivity, a high heat capacıty per unit weight, and be a poor heat conductor.

5. The material should be chemically stable when exposed to high temperature air.

6. The extremely low resistivity of the generator means that the emitter and collector material should be good electrical conductors.

of the materials tested, graphite was the only one which met to some degree the required properties. This material, however, does possess two fairly serious drawbacks, namely: 
1. Low emitting capabilities.

2. Lowering of the work furction with respect to temperature. Both conditions seriousiy limit the power output.

Thoriated tungster and tungsten are chemically unstable in high temperature air. This Instability was pronounced during the experiment. With the use of either a thorlated tungsten or a tungsten emitter or collector, a bluish compound would cover the surface of these materials. If the oxygen content was high enoigh, a yellowish deposit would then plate itself on top of the first deposit. The bluish material was always present after the gererator had been in cperation. The yellowish deposit was accidentally discovered when an air leak occurred in the chamber. The leak evidently caused a sufficient increase in the oxygen content to precipitate this compound. A chemical analysis of these compoxnds indicated that both were tungsten trioxide. The yellowish material possessed a very high resistivity, and therefore seriously affected the operation of the gererator. The bluish material performed more like a semiconducting compound in that its resistivity was higher than the tungsten metal but was rot high enough to be considered as an irsulator. The main effect of this particular compound seemed to be in a slight increase in the work function of thorlated tungsten and a decrease in the work. function of tungsten.

Thoriated tungster and tungsten also possess another serious drawback. As the temperature of the nose approaches 
$2000^{\circ} \mathrm{K}$, both of these materials vaporize at a fairly high rate. The insulator, being considerably cooler, has a thin film of tungsten deposited on its surface. After two or three minutes of operation, an insulator of $1 / 2$ inch in length is sufficiently covered so as to cause a low impedance path between emitter and collector.

Another factor is that these materials lose their shape as the temperature begins to exceed $2500^{\circ} \mathrm{K}$.

Molybdenum, which was also tried as an emitter and collector. proved to be chemically unstable. This material has a very high chemical reaction rate. After five or ten seconds of operation, the collector was sufficiently covered with an insulating compound to completely prevent any electron flow. 
Table 1

\begin{tabular}{|c|c|c|c|c|c|c|c|c|c|c|}
\hline$Y(f t)$ & $\begin{array}{l}V(\mathrm{ft} / \\
\text { sec) }\end{array}$ & $\begin{array}{l}q_{S}(B T U / \\
\text { sec } 1 \mathrm{t} 3 \text { ) }\end{array}$ & $q_{i-e}$ & $\mathrm{~T}_{\mathrm{g}}^{\circ} \mathrm{K}$ & 72 & $\begin{array}{c}J_{i}(\operatorname{amps} / \\
s q \pm t)\end{array}$ & $\begin{array}{l}I_{\mathrm{s}}(\operatorname{amps} / \\
\mathrm{sq} \text { ft })\end{array}$ & $\begin{array}{c}I(\text { amps } / \\
\text { sq } \mathrm{It})\end{array}$ & $\begin{array}{r}v(\text { volts } / \\
\text { sq } \mathrm{tt})\end{array}$ & $\begin{array}{r}P \text { (watts) } \\
\text { sq ft) }\end{array}$ \\
\hline 300000 & 24999 & 1387 & .607 & 5700 & $(4)(10)^{12}$ & 45.5 & 12.25 & 0 & .117 & 0 \\
\hline 290000 & 24998 & 1751 & .61 & 5800 & $(4)(10)^{12}$ & 46.0 & 50.9 & 8.89 & .121 & 1.08 \\
\hline 280000 & 24998 & 2211 & .914 & 5800 & $(6)(10)^{12}$ & 68.7 & 200.0 & 35.0 & .197 & 6.89 \\
\hline 270000 & 24997 & 2792 & 1.22 & 5800 & $(8)(10)^{12}$ & 92.0 & 667.0 & $116 \cdot 3$ & .290 & 33.7 \\
\hline 260000 & 24996 & 3525 & 1.535 & 5900 & $(1)(10)^{13}$ & 1.15 .7 & 5500.0 & 960.0 & .355 & 351.0 \\
\hline 250000 & 24994 & 4452 & 3.09 & 6000 & $(2)(10)^{13}$ & 233.0 & 6300 & 1100 & .374 & 412.0 \\
\hline 240000 & 24990 & 5621 & 6.3 & 6200 & $(4)(10)^{13}$ & 475 & 6300 & 1100 & .375 & 413 \\
\hline 230000 & 24985 & 7096 & 9.6 & 6400 & $(6)(10)^{13}$ & 723 & 6300 & 1100 & .372 & 410 \\
\hline 220000 & 24977 & 8955 & 12.9 & 6500 & $(8)(10)^{13}$ & 971 & 6300 & 1100 & .362 & 398.5 \\
\hline 210000 & 24964 & 11294 & 16.25 & 6600 & $(1)(10)^{14}$ & 1225 & 6300 & 1100 & .354 & 390 \\
\hline 200000 & 24944 & 14230 & 16.4 & 6700 & (1) $(10)^{14}$ & 1235 & 6300 & 1100 & .365 & 402 \\
\hline 190000 & 24911 & 17901 & 16.4 & 6700 & $(1)(10)^{14}$ & 1235 & 6300 & 1100 & .365 & 402 \\
\hline 180000 & 24859 & 22462 & 32.3 & 6500 & $(2)(10)^{14}$ & 2440 & 6300 & 1100 & .267 & 294 \\
\hline 170000 & 24777 & 28072 & 65.4 & 6700 & $(4)(10)^{14}$ & 4920 & 6300 & 1100 & .205 & 225.5 \\
\hline 160000 & 24647 & 34859 & 100.5 & 7000 & $(6)(10)^{14}$ & 7550 & 6300 & 1100 & .182 & 200.5 \\
\hline 150000 & 24440 & 42846 & 170.5 & 7300 & $(1)(10)^{15}$ & 12870 & 6300 & 1100 & .152 & 167.2 \\
\hline 140000 & 24114 & 51810 & 347.0 & 7500 & $(2)(10)^{15}$ & 26100 & 6300 & 1100 & .114 & $125 \cdot 3$ \\
\hline 130000 & 23602 & 61039 & 668.0 & 7000 & $(4)(10)^{15}$ & 50400 & 6300 & 1100 & .054 & 59.4 \\
\hline 120000 & 22807 & 68982 & 1003.0 & 7000 & $(6)(10)^{15}$ & 75600 & 6300 & 1100 & .043 & 47.2 \\
\hline 110000 & 19992 & 62741 & 1307.0 & 6700 & $(8)(10)^{15}$ & 98500 & 6300 & 1100 & .037 & 40.7 \\
\hline 100000 & 17923 & 54807 & 307.0 & 5900 & $(2)(10)^{15}$ & 231.00 & 6300 & 1100 & .006 & 6.6 \\
\hline 90000 & 15219 & 40675 & 119.5 & 5600 & $(8)(10)^{14}$ & 9000 & 6300 & 1100 & .057 & 62.7 \\
\hline 80000 & 11902 & 23821 & .814 & 4600 & $(6)(10)^{12}$ & 61.0 & 6300 & 1.100 & .209 & 230.0 \\
\hline
\end{tabular}




\section{Takie 2}

Experimental Resuits Hypersonic Plasma Thermionic Generator Run No. 174 Date: August 6, 1962

$\Delta \mathrm{r}: .05 \Omega$

Insulator length: $1 / 2$ irch

Model located $I$ inch from the nozzle.

\begin{tabular}{|c|c|c|c|}
\hline I (amps) & $\begin{array}{l}\because(v o z t s) \\
\text { Measured }\end{array}$ & $\begin{array}{l}v(v c I t s) \\
\text { corrected }\end{array}$ & $\begin{array}{l}\text { Power } \\
\text { (watts) }\end{array}$ \\
\hline 33.3 & -5.63 & -3.97 & \\
\hline 31.3 & -4.75 & -3.19 & \\
\hline 29.14 & -3.75 & $-2 \cdot 30$ & \\
\hline 25.8 & -2.875 & -11.583 & \\
\hline 9.24 & .075 & .536 & 4.95 \\
\hline 8.40 & .30 & .720 & 6.05 \\
\hline 7.21 & .55 & .91 & 6.57 \\
\hline 5.80 & .775 & 1.065 & 6.1 .8 \\
\hline 4.72 & 1.00 & $=.235$ & 5.84 \\
\hline 3.58 & 1.26 & 2.44 & 5.16 \\
\hline 2.90 & 1.41 & 1.555 & 4.52 \\
\hline 2.32 & 1.565 & 1.685 & 3.92 \\
\hline 1.78 & $\therefore .655$ & 2.744 & 3.10 \\
\hline 1.00 & 1.855 & 1.905 & 1.905 \\
\hline$\cdot 7$ & 1.940 & 1.975 & 1.383 \\
\hline 0 & 2.15 & 2.15 & 0 \\
\hline
\end{tabular}


Table 3

Computed Results Hypersonic Plasma Thermioric Generator

Material: Graphite Emitter and Graphite Collector.

$I_{s}+I_{p l}=33.3$ amps NOTE: Corresponds to run No. 174 $I_{\mathrm{p} 2}=6.5 \mathrm{amps}$

\begin{tabular}{lcccccc}
\hline$I$ & & & $\frac{\mathrm{kT}}{\mathrm{e}}$ & $\varphi_{\mathrm{e}}^{-\varphi_{\mathrm{a}}}$ & $\mathrm{I}_{x}$ & $\mathrm{~V}$ \\
\hline 33.3 & 3944 & -8.25 & -10.35 & 0 & 0 & -10.35 \\
31.3 & -19.0 & -2.94 & -3.69 & 0 & 0 & -3.69 \\
29.14 & -8.6 & -2.15 & -2.7 & 0 & 0 & -2.7 \\
25.8 & -4.32 & -1.465 & -1.84 & 0 & 0 & -1.84 \\
9.24 & -1.521 & .42 & .527 & 0 & 0 & .527 \\
8.40 & 1.67 & .513 & .645 & 0 & 0 & .645 \\
7.21 & 1.9 & .641 & .806 & 0 & 0 & .806 \\
5.80 & 2.26 & .802 & 1.008 & 0 & 0 & 1.008 \\
4.72 & 2.55 & .937 & 1.176 & 0 & 0 & 1.176 \\
3.58 & 2.95 & 1.082 & 1.36 & 0 & 0 & 1.36 \\
2.90 & 3.22 & 1.17 & 1.47 & 0 & 0 & 1.47 \\
2.32 & 3.51 & 1.253 & 1.576 & 0 & 0 & 1.576 \\
1.78 & 3.82 & 1.34 & 1.685 & 0 & 0 & 1.685 \\
1.00 & 4.35 & 1.47 & 1.845 & 0 & 0 & 1.845 \\
.7 & 4.53 & 1.51 & 1.895 & 0 & 0 & 1.895 \\
0 & 5.16 & 1.64 & 2.06 & 0 & 0 & 2.06 \\
\hline
\end{tabular}

To obtain $\mathrm{T}_{\mathrm{e}}$

$$
\begin{aligned}
& \frac{e}{\mathrm{kT}_{e}}=\frac{4.35-2.55}{1.905-1.236}=.798 ; \\
& \mathrm{T}_{e}=14520^{\circ} \mathrm{K} .
\end{aligned}
$$


Table 4

Experimental Results from Group 3

\begin{tabular}{lccl} 
Run No. 132 & Date: July 23, 1962 \\
$\Delta r=.043$ & & \\
Insulator length: $1 / 2$ inch & & \\
Model located I inch from the nozzle. & \\
\multicolumn{5}{l}{} & & \\
\hline I(amps) & v(volts) & v(volts) & Power \\
\hline 6.15 & measured & corrected & (watts) \\
5.30 & -2.45 & -2.19 & \\
3.78 & -1.32 & -1.092 & \\
3.56 & -.3 & -.138 & .722 \\
2.95 & .05 & .203 & 1.645 \\
2.15 & .43 & .557 & 2.06 \\
1.80 & .865 & .958 & 1.942 \\
1.27 & 1.00 & 1.0774 & 1.61 \\
.82 & 1.25 & 1.305 & 1.157 \\
.3 & 1.375 & 1.410 & .473 \\
.17 & 1.565 & 1.578 & .280 \\
0 & 1.64 & 1.647 & 0 \\
\hline
\end{tabular}




\section{Table 5}

Computed Quantities Hypersonic Plasma Thermionic Generator Material: Thoriated Tungsten Emitter and Graphite Collector $I_{s}+I_{p 1}: 6.15$ amps NOTE: Corresponds to run No. 132 $I_{p 2}: .98$ amps

\begin{tabular}{|c|c|c|c|c|c|c|}
\hline$I$ & & $\ln$ & $\frac{k T_{e}}{e} I n$ & $\varphi_{\mathrm{e}}^{-\varphi_{a}}$ & $I_{r}$ & $\mathrm{~V}$ \\
\hline 6.15 & -99 & $-4 \cdot 6$ & -2.225 & .83 & 0 & -1.395 \\
\hline $5 \cdot 30$ & $-7 \cdot 39$ & -2.0 & -.967 & .83 & 0 & -.137 \\
\hline 3.78 & -2.02 & -.703 & -.339 & .83 & 0 & .49 \\
\hline 3.56 & -1.752 & -.552 & -.2715 & .83 & 0 & .56 \\
\hline 2.95 & -1.228 & -.2055 & -.0980 & .83 & 0 & .74 \\
\hline 2.15 & 1.28 & .247 & .1192 & .83 & 0 & .95 \\
\hline 1.80 & 1.565 & .4475 & .216 & .83 & 0 & 1.046 \\
\hline 1.27 & 2.17 & .775 & .3745 & .83 & 0 & 1.2045 \\
\hline .82 & 3.875 & 1.352 & .653 & .83 & 0 & 1.483 \\
\hline .3 & 4.57 & 1.52 & .734 & .83 & 0 & 1.564 \\
\hline .17 & 5.2 & 1.55 & .796 & .83 & 0 & 1.626 \\
\hline 0 & 6.27 & 1.835 & .836 & .83 & 0 & 1.716 \\
\hline
\end{tabular}

To obtain $\mathrm{T}_{\mathrm{e}}$ :

$$
\begin{aligned}
& \frac{e}{\mathrm{kT}_{\mathrm{e}}}=\frac{\ln 6.27-\ln 4.57}{1.73-1.578}=2.07 ; \\
& \mathrm{T}_{\mathrm{e}}=5600^{\circ} \mathrm{K} .
\end{aligned}
$$



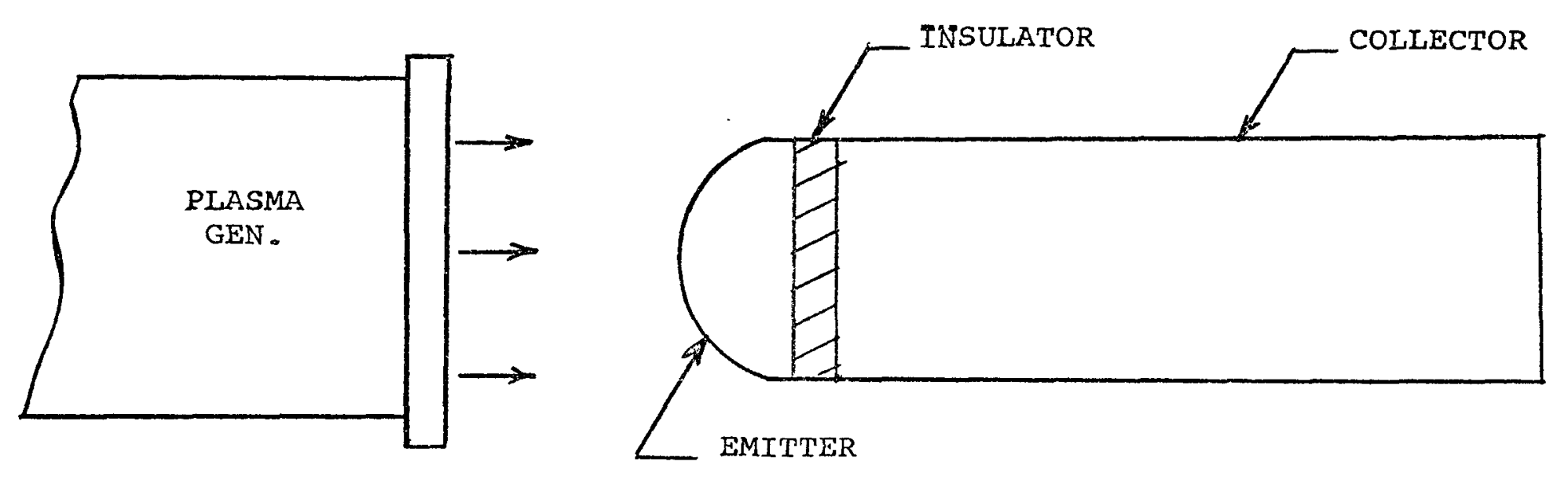


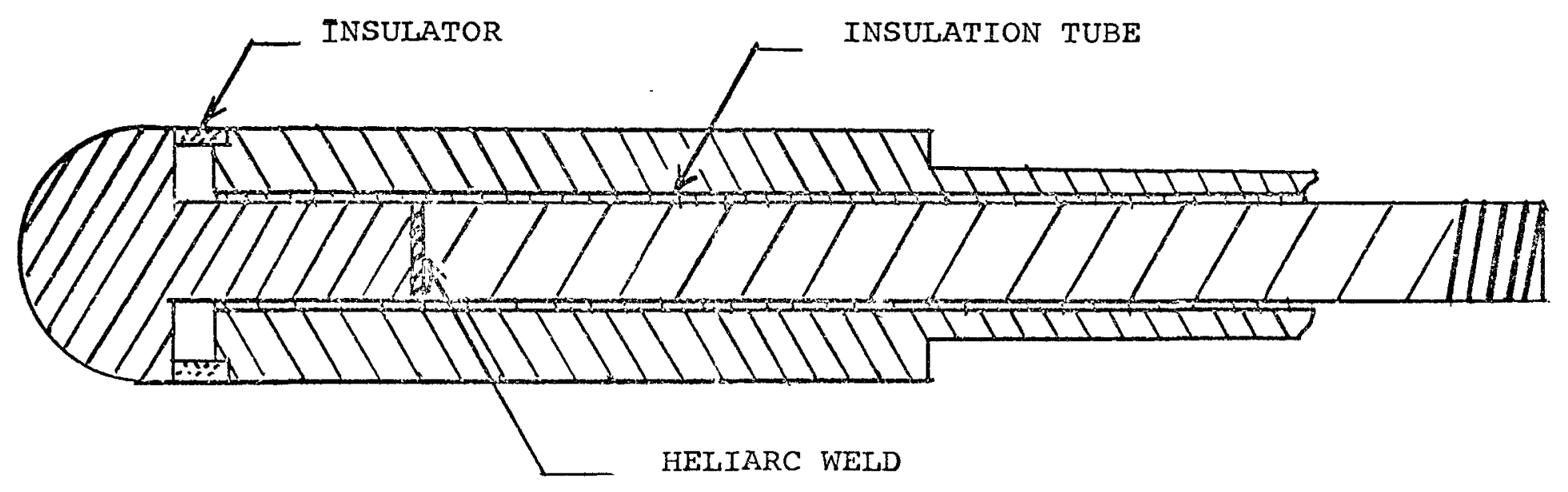

FIGURE 2 


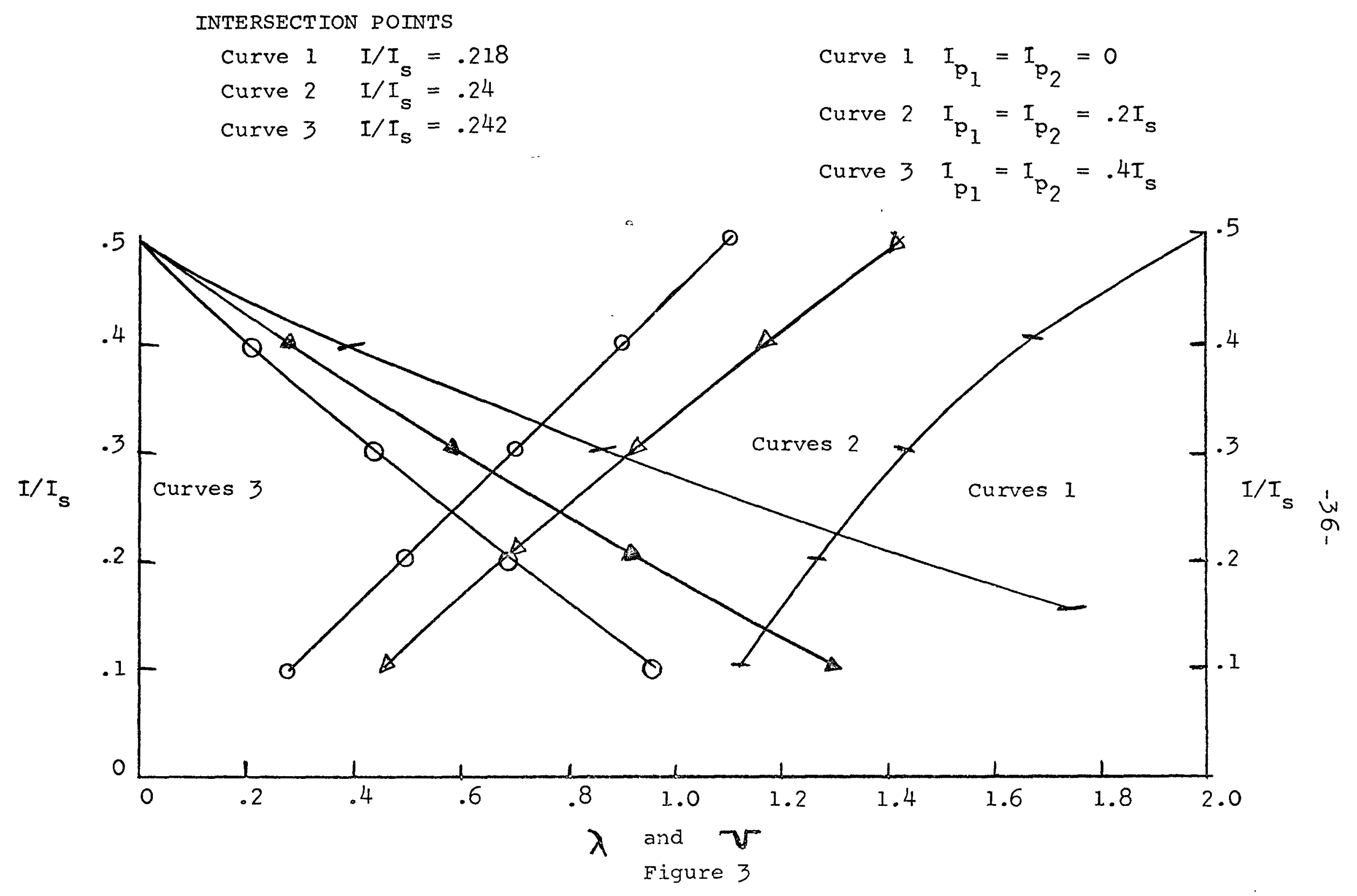


$-37-$

Model 3

Output current

VS

Output voltage

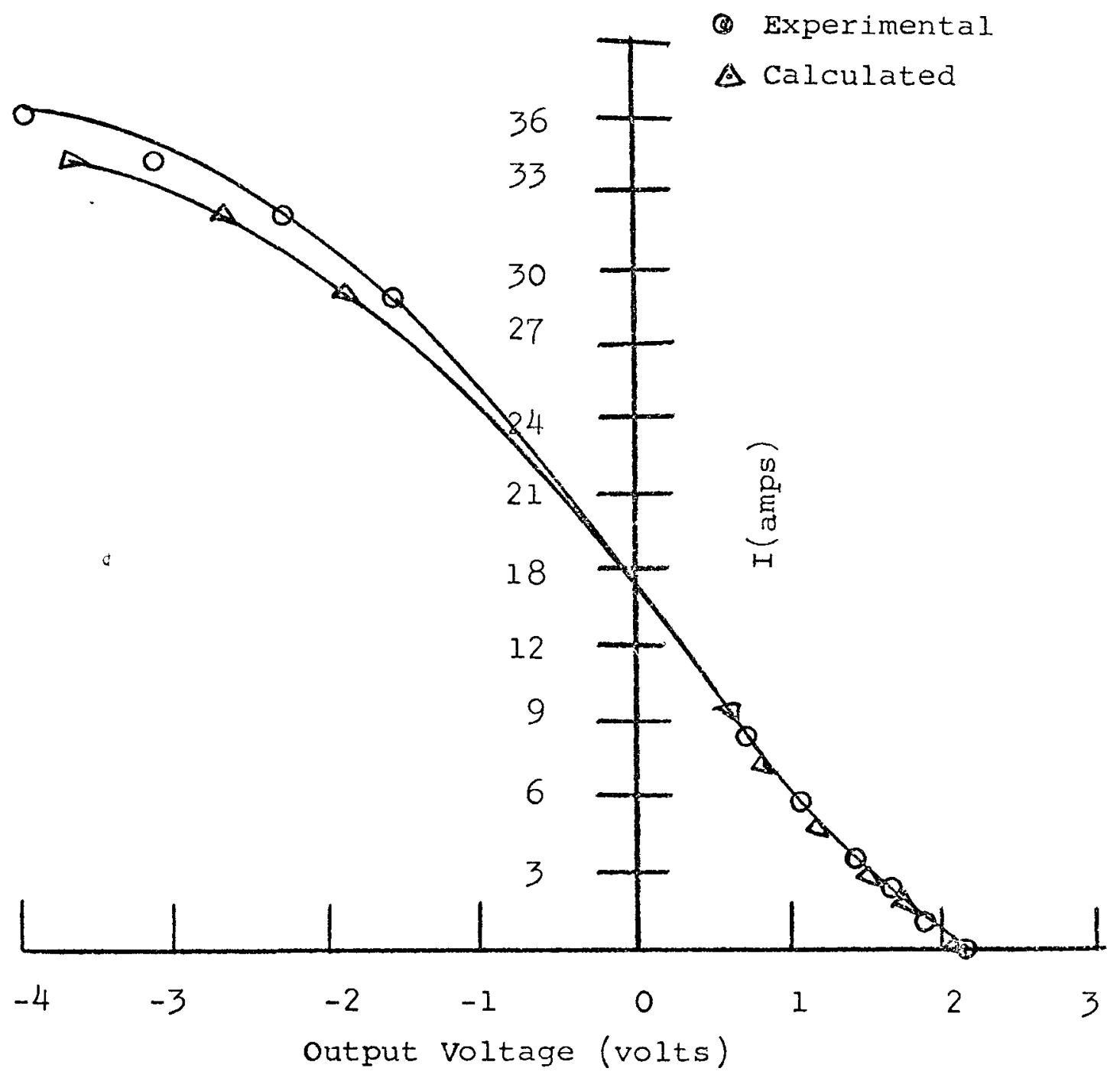

FIGURE 4 


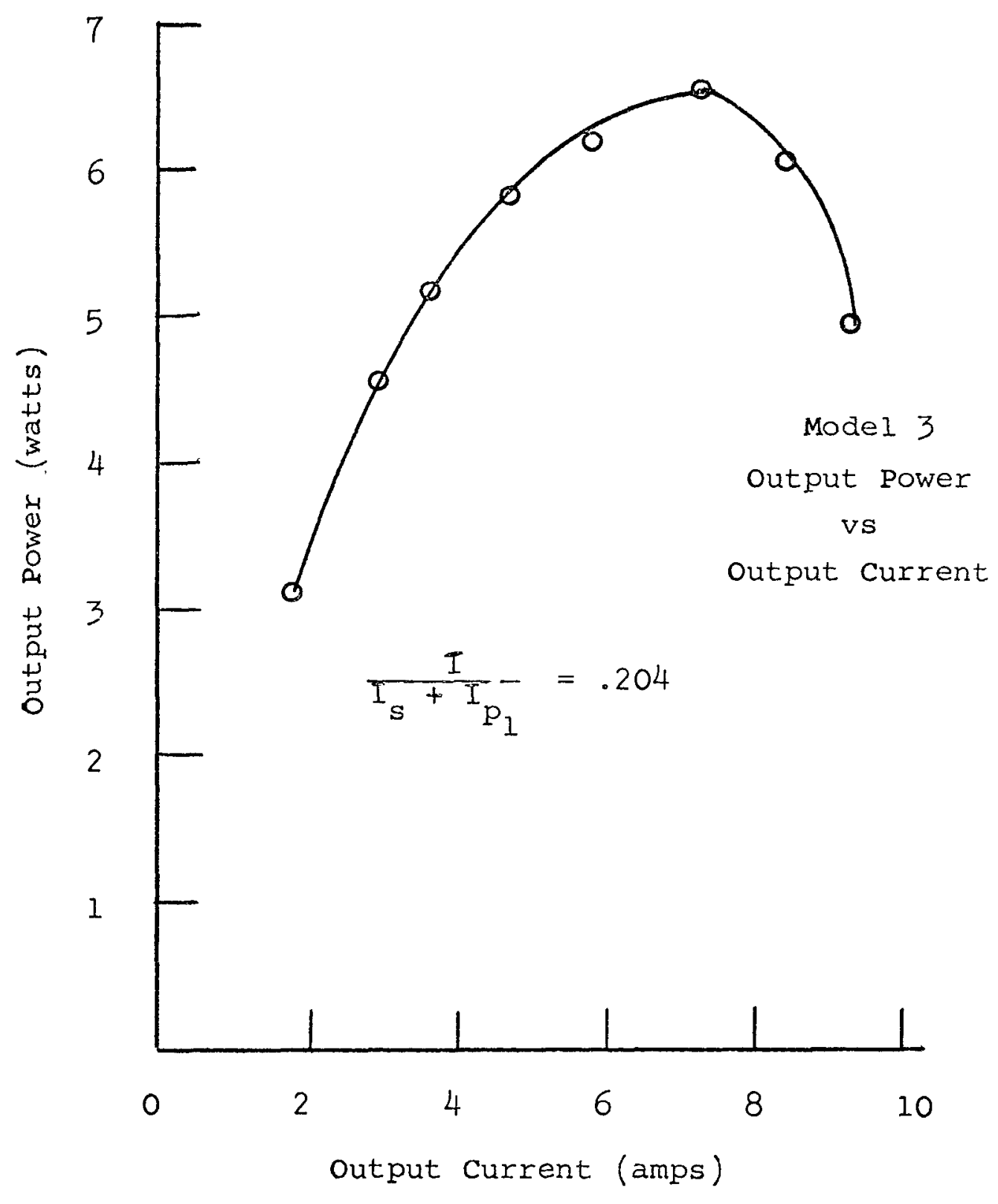

FIGURE 5 


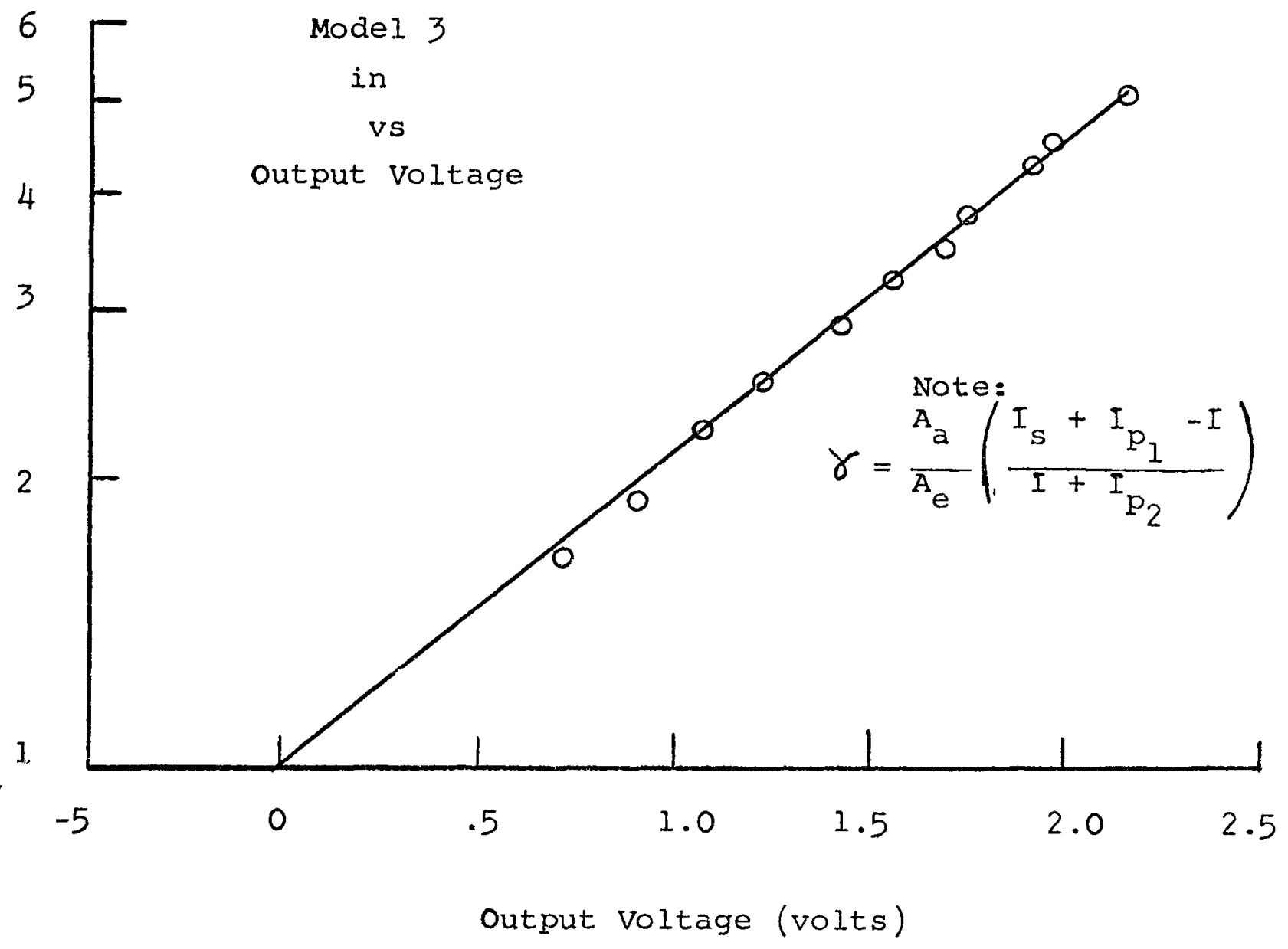

FIGURE 6 